\title{
TESTING AND BENCHMARKING OF A THREE-DIMENSIONAL GROUNDWATER FLOW AND SOLUTE TRANSPORT MODEL
}

\author{
by \\ P. N. Sims \\ Savannah River Site \\ Aiken, South Carolina 29808 \\ P. F. Andersen \\ C. R. Faust
}

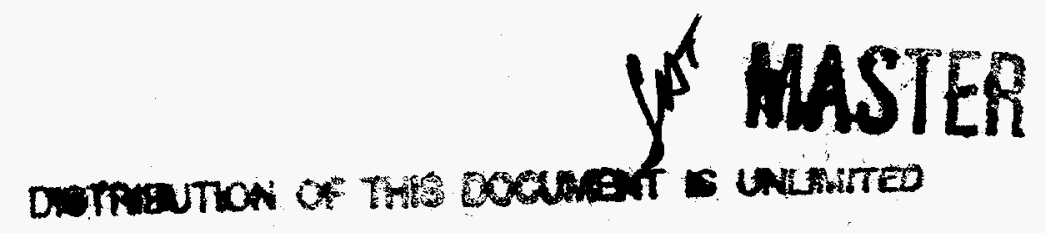

DOE Contract No. DEAC0989SR18035

This paper was prepared in connection with work done under the above contract number with the U.S.

Department of Energy. By acceptance of this paper, the publisher and/or recipient acknowledges the U.S. Government's right to retain a nonexclusive, royalty-free license in and to any copyright covering this paper, along with the right to reproduce and to authorize others to reproduce all or part of the copyrighted paper. 


\section{DISCLAIMER}

This report was prepared as an account of work sponsored by an agency of the United States Government. Neither the United States Government nor any agency thereof, nor any of their employees, makes any warranty, express or implied, or assumes any legal liability or responsibility for the accuracy, completeness, or usefulness of any information, apparatus, product, or process disclosed, or represents that its use would not infringe privately owned rights. Reference herein to any specific commercial product, process, or service by trade name, trademark, manufacturer, or otherwise does not necessarily constitute or imply its endorsement, recommendation, or favoring by the United States Government or any agency thereof. The views and opinions of authors expressed herein do not necessarily state or reflect those of the United States Government or any agency thereof.

This report has been reproduced directly from the best available copy.

Available to DOE and DOE contractors from the Office of Scientific and Technical Information, P. O. Box 62, Oak Ridge, TN 37831; prices available from (423) 576-8401.

Available to the public from the National Technical Information Service, U. S. Department of Commerce, 5285 Port Royal Road, Springfield, VA 22161. 


\section{DISCLAIMER}

\section{Portions of this document may be illegible in electronic image products. Images are produced from the best available original document.}




\title{
TESTING AND BENCHMARKING OF A THREE-DIMENSIONAL GROUNDWATER
}

\section{FLOW AND SOLUTE TRANSPORT MODEL}

\author{
P. N. Sims, ${ }^{1}$ P. F. Andersen, ${ }^{1}$ D. E. Stephenson, ${ }^{2}$ and C. R. Faust ${ }^{1}$ \\ ${ }^{1}$ GeoTrans, Inc. \\ Herndon, Virginia 22070 \\ ${ }^{2} E$. I. du Pont de Nemours and Co. \\ Aiken, South Caroina 29808
}

A three-dimensionai finite-difference model was developed to simulate groundwater flow and solute transport processes in fully saturated media. The model is intended for application to a variety of complex sites at the Savannah River Plant (SRP), a major Department of Energy (DOE) facility in South Carolina. The model solves the flow and transport equations separately. Transport mechanisms considered include: advection, hydrodynamic dispersion, and adsorption. The model uses a block-centered finite-difference grid that allows variable spacing and the approximation of irregular geometry. The model also allows the approximation of layers that have irregular thickness and/or that are not horizontal.

To verify the accuracy of the numerical formulation, the model was tested using five problems having analytical solutions. The final problem also investigated the effects of grid orientation and lumping of cross-product terms.

The model was also run for more complex problems not amenabie to analytical solutions. For these problems, the results were compared to those computed by other publicly available models that have been used for large field problems. The benchmarking procedure compared the results of two finite-difference codes and one finite-element code. The codes were used to calculate the response of three multilayer field problems. The finite-difference modeis showed excellent comparison for two of the problems and a fair comparison for the remaining probiem. Differences in the results are attributed to the different formulations for perched water table conditions. The finite-element comparison was aiso quite good, but as expected, this solution technique resulted in greater drawdown calculated in the vicinity of the pumping wells and less away from the wells than the finite-difference methods. For the problem considered, the finite-difference models were more efficient 
than the finite-element model. To further assess efficiency and differences between models, a finite-element model using influence coefficient techniques was also evaluated. Using this code, results similar to the original finite-element model were obtained with a reduction in CPU time.

It was concluded from the benchmarking of the various codes that the finite-difference model, which was developed for application to complex hydrogeologic systems, performed very well when compared to other accepted groundwater flow and transport codes applied to the same field problems. The model also proved to be efficient in comparison with the others used.

\section{INTRODUCTION}

A three-dimensional finite-difference model was developed to simulate groundwater flow and solute transport. The model is intended for application to a variety of groundwater resource and solute migration evaluations, including several complex sites at the Savannah River Plant (SRP). SRP is a major Department of Energy (DOE) facility in South Carolina. Because the mode1, FTWORK, is relatively new, there is a need to provide confidence in the model results. Methodologies that test models include comparisons with analytical solutions, comparisons with empirical data, and checking that conservation properties hold. Another level of testing is the comparison of one code against another. This paper describes the testing and benchmarking procedure used to verify and validate FTWORK.

\section{PURPOSE}

FTWORK is a new three-dimensional finite-difference model for simulation of flow and solute transport processes in fulty saturated porous media (GeoTrans, 1987). FTWORK provides an alternative to more comprehensive models such as SWIFT II (Reeves et al., 1986) and HST3D (Kipp, 1987). Unlike these models, the flow equation is posed in terms of hydraulic head. The hydraulic head formulation is more convenient than the pressure formulation for most groundwater and hazardous waste assessments. FTWORK is easier to use in terms of input and operation because many of the complexities of more comprehensive codes (density dependence, heat transport, deformation, etc.) are not considered. FTWORK is highly compatible with the popular groundwater flow model, MODFLOW (McDonald and Harbaugh, 1984), in terms of equation and finitedifference formulation, allowing transfer of input data between the two codes.

In summary, FTWORK is intended to facilitate the application of a solute transport model by eliminating evaluation of the processes which are rareiy important in real-world assessments of groundwater flow and contaminant transport and by formulating the equations in terms of units and parameters frequently used by hydrologists. 


\section{FEATURES}

The three-dimensional model is based on a finite-difference scheme utilizing a block-centered grid that allows variable spacing and approximation of irregular geometry. The model also allows approximation of 1 ayers that have irregular thickness and/or that are not horizontal.

For unconfined conditions the transmissivity term is a function of the saturated thickness in adjacent blocks. A simple approach for treating non-linear terms is used that is suitable for applications where the non-linearity is mild. This technique is not designed to accomodate severe non-linearities such as those associated with rapid desaturation or resaturation of the aquifer. This model does not include a procedure for resaturation of grid blocks. If a grid block becomes desaturated during any iteration, the grid block is dropped from the solution set.

This model includes two optional geometrical approximations. The first option permits approximation of aquitards between grid block layers. The second option provides approximation of layers that have variable thickness and variable elevations. The aquitard and variable thickness/elevation options may be specified together or separately.

The equations for flow and solute transport are coupled due to the advective and accumulation terms in the transport equation. These terms are dependent upon head. Because it is assumed that density is independent of concentration, no terms in the flow equation depend on concentration. Thus, the flow equation can be solved independently of solute transport but the solute transport equation must be solved in conjunction with the flow equation. Many applications involve steadyflow but unsteady solute transport. FTWORK also provides options to simulate a completely unsteady flow and transport situation or to simulate a series of steady flow fields with unsteady solute transport. The latter condition is of practical interest for aquifers in which historical pumping has increased in increments. No matter which type of simulation is required, the finite-difference equations are decoupled by first solving the flow equation for heads. The head values required in the transport simulation are then explicitly specified.

For general three-dimensional problems, an iterative method is used to solve the flow and transport equations. This method, slice Successive Over-Relaxation (SSOR), is a subset of the more general method of block successive overrelaxation (Woo and Emanuel, 1976). For a detailed description of SSOR, see Wattenbarger and Thurnau (1976). SSOR is similar to line successive overrelaxation in two dimensions, except that instead of solving each row implicitly, each vertical sice of the grid is solved implicitly. For flow, the three-dimensional equations have seven unknowns per equation (grid block). The transport system has 19 unknowns for each grid block. The SSOR method divides the system of equations as follows: five coefficients are treated implicitly for flow and nine coefficients are treated implicitly for transport. 
The matrix equation for each slice is solved using the GaussDoolittle method (Weaver, 1967) for banded coefficient matrices. The coefficient matrix for the flow equation is symmetric but the coefficient matrix for the transport equation is nonsymmetric. FTWORK includes two alternative equation solvers so that extra computational work is not performed for the flow solution. Also, because the coefficient matrix does not change during a time step or nonlinear iteration, the matrix decomposition is performed only on the first SSOR iteration. On subsequent SSOR iterations, forward and back substitutions are performed. This procedure results in a substantial computational savings because matrix decomposition requires many more computations than forward and backward substitutions. Convergence of the SSOR scheme is checked in absolute terms for flow and normalized terms for solute transport.

Processes considered for solute transport include dispersion, a linear equilibrium adsorption isotherm, and first order decay. cross product terms for hydrodynamic dispersion can be included in the transport calculations. As illustrated in a subsequent section, inclusion of cross-product terms can provide a significant improvement in the accuracy of transport calculations. The model has an option to use either central or upstream weighting of the advection term and central or backwards weighting of the time derivative.

A Gauss-Newton technique for non-1 inear least-squares parameter estimation has been incorporated into solution of the flow equation for automatic history matching.

A comprehensive mass balance is included in the code for both flow and transport. A layer-by-layer balance is also included for multiaquifer simuiations.

\section{MOOEL TESTING METHODOLOGY}

Two levels of testing were preformed on the FTWORK code. In the preliminary testing, five problems with analytical solutions were used. These problems were selected to allow verification of distinct features of the FTWORK code. For each problem realistic values of physical parameters were used. The five problems are as follows:

1. Flow to parailel drains in an unconfined aquifer subjected to vertical recharge (Bear, 1979, p 180).

2. Transient flow to a drain in a semi-infinite aquifer due to a step change in head (Venetis, 1968).

3. Unsteady drawdown in a confined aquifer near a recharge boundary (Theis, 1935).

4. One-dimensional solute transport (Ogata and Banks, 1961).

5. Two-dimensional transport from a point source in a uniform flow field (Wilson and Miller, 1978). 
These problems are discussed in the next section of the paper. Comparison of resuits provides an indication of the codes ability to model a particular process. Good comparison of modeled results to analytical provides confidence that the code can model these processes under less restrictive assumptions and boundary conditions. This confidence is enhanced by testing the model on field problems.

The advanced level of testing involved comparing the results of various field problems simulated by FTWORK to resuits obtained form other computer codes. Three computer codes were used in the benchmarking process: MODFLOW, SWIFT, and CFEST (McDonald and Harbaugh, 1984; Reeves et a1., 1986; Gupta et a1., 1987; respectively). of these three codes, two are based on finite-difference methods (MODFLOW, SWIFT) and one on the finite-eiement method (CFEST). Three problems were run with FTWORK and resuits compared to the appropriate codes. These problems are:

6. Drawdown in a muitilayer aquifer system subject to several transient stresses (Andersen et al., 1984).

7. Steady state groundwater flow regime of the General Separations Area, Savannah River Plant (Duffield et al., 1987).

8. Transport of a conservative species in a steady state flow field at the General Separations Area, Savannah River Plant (Duffieid et ai., 1987).

These problems are discussed in a later section of this paper. The problems provide a good test of many of the codes features because they are fairly complex and representative of the types of problems most often encountered. The inability of the codes to provide identical results should not be surprising, however any deviations should be justifiable.

\section{COMPARISON TO ANALYTICAL SOLUTIONS}

Table 1 shows the attributes of FTWORK that were tested in the simulations where results were compared to analytical solutions. The five probjems tested most of the basic features of a groundwater flow and solute transport modet. In all cases, comparison of modeted results to analytical results was good.

For the purpose of brevity, oniy one of the five problems having anaiytical solutions that were used in the testing process is discussed in this section. 
Table 1. Summary of attributes tested in the comparisons to analytical solutions.

\begin{tabular}{|c|c|c|c|c|c|c|c|c|c|c|c|c|c|c|}
\hline \multirow[b]{2}{*}{ Probiem } & \multicolumn{6}{|c|}{ Thoundare Condtiont } & \multicolumn{2}{|c|}{1 Aquifer Condunoms } & \multicolumn{2}{|c|}{ I Jemponi Charactersalke } & \multicolumn{2}{|c|}{ T Limenstonative } & \multicolumn{2}{|c|}{ Ecuaron solved } \\
\hline & 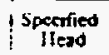 & Wells & Recharge & No Flom & $\begin{array}{l}\text { Socerfied } \\
\text { Stast fiws }\end{array}$ & $\begin{array}{c}\text { Spectived } \\
\text { Concentration }\end{array}$ & I Unconfimes & Confiand & $\begin{array}{l}\text { Sremoy } \\
\text { Siat: }\end{array}$ & Irantient: & 10 & 20 & Flow & Trangene \\
\hline . & $x$ & & $\bar{x}$ & $\bar{x}$ & & & $\bar{x}$ & & $\bar{x}$ & & $\bar{x}$ & & $x$ & \\
\hline 2 & $x$ & & & $x$ & & & & $x$ & & $x$ & $x$ & & $1 x$ & \\
\hline 3 & $x$ & $x$ & & $x$ & & & & $x$ & & $x$ & $i$ & $r$ & $1 x$ & \\
\hline 4 & $x$ & & & & & $x$ & & $x$ & & $x$ & $x$ & & $x$ & $x$ \\
\hline 5 & $\mathbf{i}$ & $x$ & & $x$ & $x$ & & & $x$ & & $x$ & & $x$ & $i x$ & $x$ \\
\hline
\end{tabular}

Two-Dimensional Transport from a Point Source in a Uniform Flow field

This problem describes the two-dimensional transport of solute from a point source in a uniform flow field. In practice, the idealjzed conditions are analogous to continual leakage or injection of a solute into an aquifer from a point source such as a small leaking landfill or an improperly sealed wall. The rate of fluid leakage or injection into the aquifer is negligible relative to the naturai groundwater flow. In sumnary, the assumptions include:

1. uniform groundwater flow velocity

2. uniform dispersivity $\left(\alpha_{Q}\right.$ and $\left.\alpha_{T}\right)$

3. continuous point source of solute

4. infinite aquifer extent

The initial and boundary conditions for this problem are

$$
\begin{aligned}
& C(x, x, 0)=0 \\
& Q_{c}(x, y, t)=Q C_{0} \delta(x, y) \\
& C( \pm \infty, \pm \infty, t)=0
\end{aligned}
$$

where $Q$ is the volumetric injection rate of fiuid per unit aquifer $\left(L^{2} / t\right), C_{0}$ is the concentration of the injected fluid $\left(M / L^{3}\right)$ and $\delta(x, y)$ is the Dirac delta function $\left(L^{-2}\right)$. The analytical solution for this problem is given by Wilson and Miller (1978).

This solution provides a basis for testing implementation of the cross-product approximations (e.g., $\frac{\partial}{\partial x} D_{x y} \frac{\partial C}{\partial y}$ ), and grid orientation effects due to the advective-terms approximation. To perform these tests, two alternative grid orientations were used (see Figure l). The first grid is aligned parallel to the groundwater flow direction. The second grid is oriented at a $45^{\circ}$ angle to the direction of groundwater flow. Due to tensorial nature of the dispersion coefficient cross-product terms are introduced for the second grid, but 
not for the first grid. Values of the physical parameters and the finite-difference grid and time step data used in the simulations are presented in Table 2 .

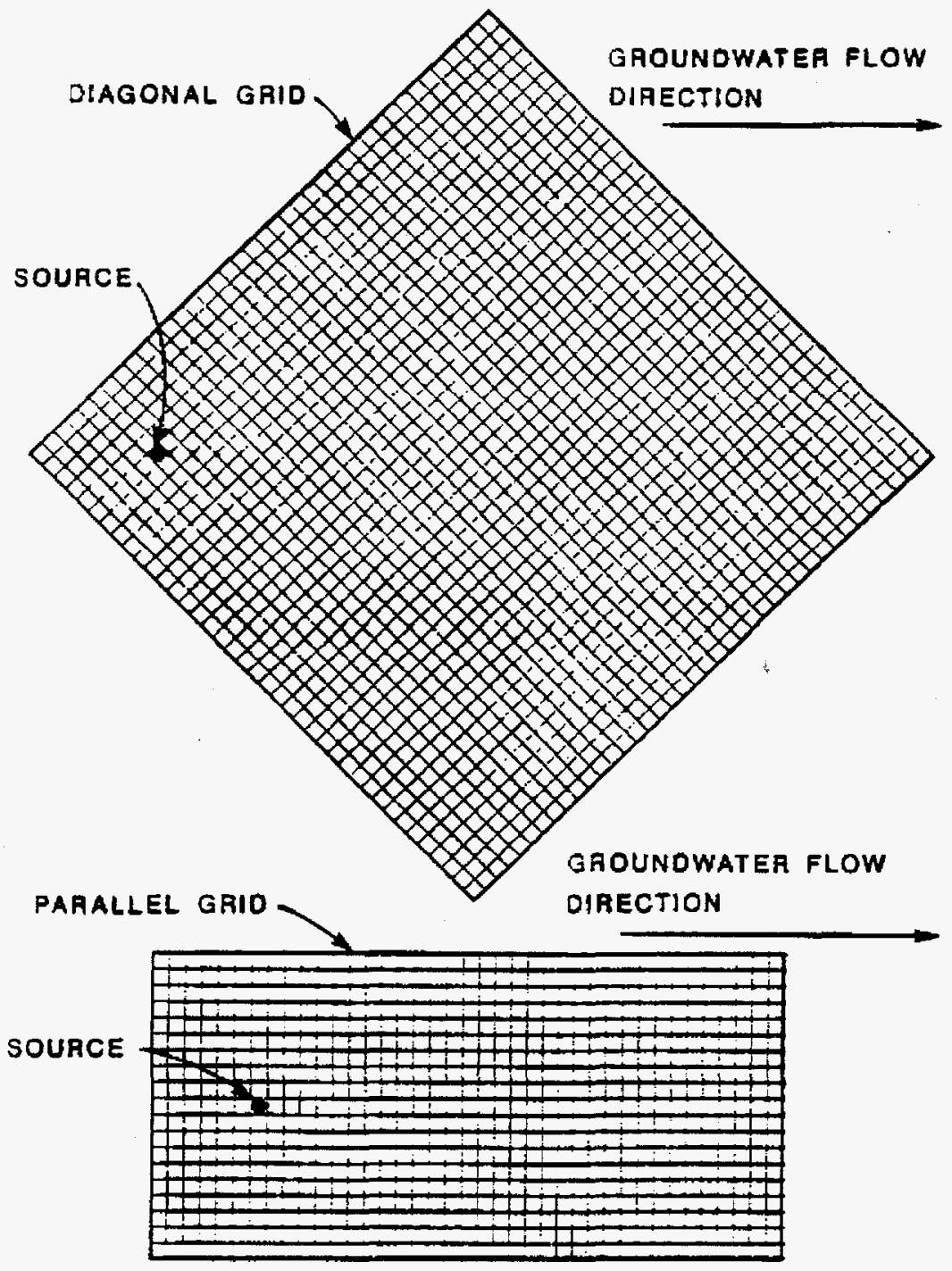

Figure 1. Alternative finite-difference discretization for Problem 5. 
Table 2. Values of the physicai parameters and the finitedifference grid and time-step data used in the twodimensional transport problem.

\begin{tabular}{ll}
\hline \multicolumn{1}{c}{ Parameter } & Value \\
\hline Darcy velocity, $V$ & $0.161 \mathrm{~m} / \mathrm{d}$ \\
Porosity, $\phi$ & 0.35 \\
Longitudinal dispersity, $\alpha_{L}$ & $21.3 \mathrm{~m}$ \\
Transverse dispersivity, $\alpha_{T}$ & $4.3 \mathrm{~m}$ \\
Aquifer saturated thickness, $b$ & $33.5 \mathrm{~m}$ \\
Contaminant mass flux, $Q C_{0}$ & $704 \mathrm{~g} /(\mathrm{m} . \mathrm{d})$ \\
Retardation coefficient, $R$ & 1.0 \\
Decay constant, $\lambda$ & $0.0 / \mathrm{d}$ \\
& \\
Selected grids: & \\
Parallel grid $-\Delta x=30 \mathrm{~m}, \Delta y=30 \mathrm{~m}, 19 \times 39 \mathrm{grid}$ \\
Diagonal grid $-\Delta x=30 \mathrm{~m}, \Delta y=30 \mathrm{~m}, 39 \times 39 \mathrm{grid}$ \\
Time steps:
\end{tabular}

The computed concentration in the direction of groundwater flow along a line through the source is compared to the analytical solution in Figure 2. The resuits show a good comparison between the analytical solutions and the numerical results for the grid oriented parallel to groundwater flow. The noticeable difference between the results of the two al ternative grids demonstrates that grid orientation effects occur even though the cross-product terms are included explicitly in the numerical model. The difference between results based on the full expansion of the cross-product terms and "Tumping" of the cross-product term illustrates that the inclusion of the cross-product approximation significantly improves the numerical solution. The lumping approximation is commonly used in finite-difference models (Kipp, 1986 and Reeves et al., 1986) to accomodate matrix solution requirements. For this example, the lumping approximation greatly overestimates transverse dispersion and is unacceptable. 


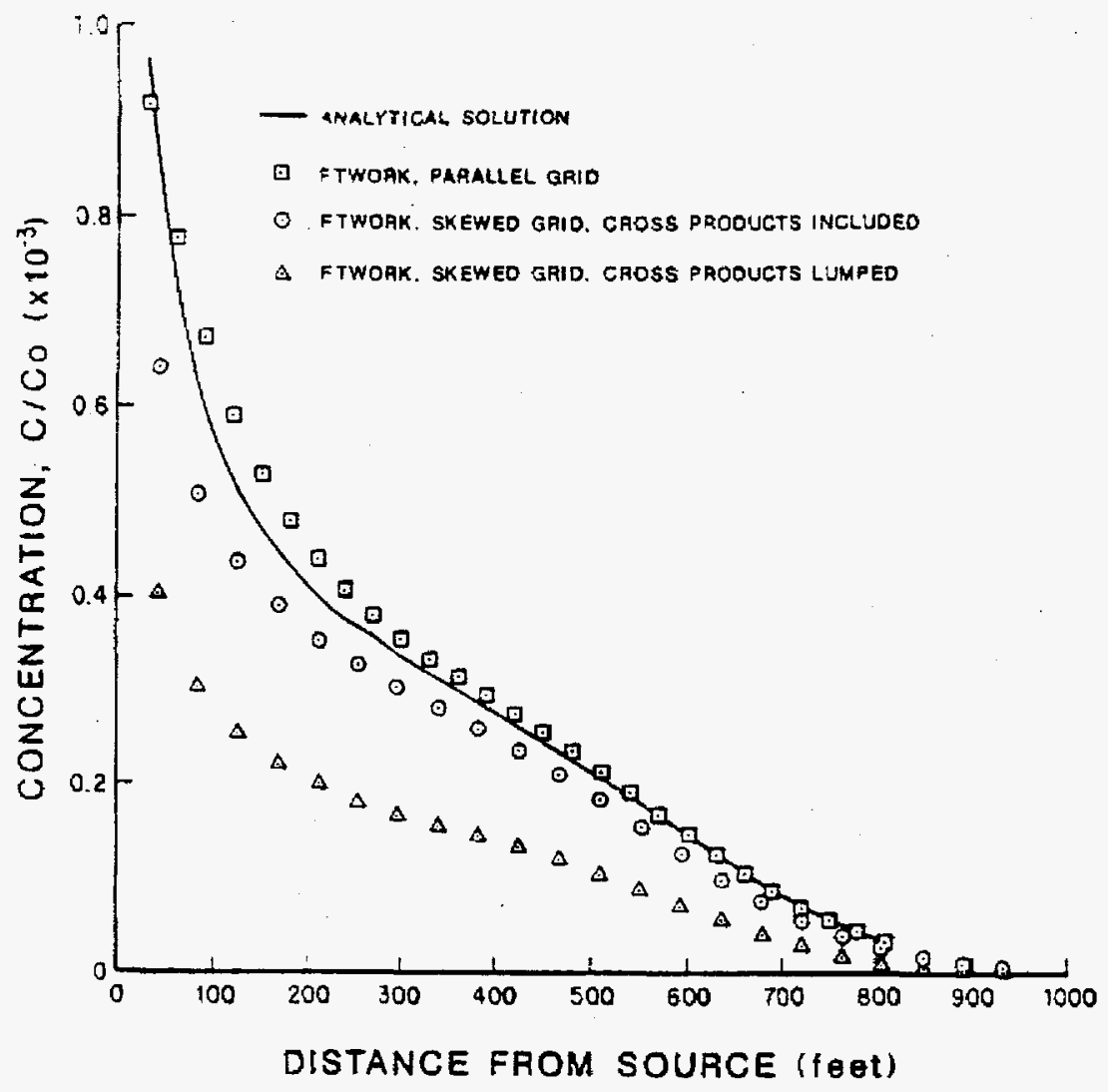

Figure 2. Comparison of FTWORK and analytical solutions for Problem 5 along the plume centerline; various combinations of grid orientation and dispersion tensor formulations.

\section{COMPARISON TO OTHER CODES}

Although the initial testing of the model provided confidence that the equations were properly formulated and implemented into the code, additional testing was necessary to assess its performance under conditions commonly found in real world situations. The next series of problems were complex, three-dimensional, and invoived irregular geometries and a multitude of boundary conditions. FTWORK results were compared to the results of other modeis because analytical solutions were not available for these problems. Table 3 shows the codes that were used for various problems. For the purposes of brevity, only one problem is discussed in detail, the second and third problems are summarized. 
Tabie 3. Codes applied to the problems under consideration.

\begin{tabular}{r|c|c|c|c}
\hline \hline & FTWORK & MODFLOW & SWIFT II & CFEST \\
\hline Problem 6 & $\mathrm{X}$ & $\mathrm{x}$ & & $\mathrm{x}$ \\
Probiem 7 & & $\mathrm{x}$ & & \\
4 layer & $\mathrm{X}$ & $\mathrm{x}$ & $\mathrm{x}$ & \\
7 Tayer & $\mathrm{X}$ & & $\mathrm{x}$ & \\
Probiem 8 & & & & \\
\hline \hline
\end{tabular}

Drawdown in a Regional Multilayer System Subject to Several Transient Stresses

This problem is based upon a study performed to investigate the importance of confining bed parameters on the magnitude and extent of drawdown in a surficial aquifer system overlying a stressed bedrock aquifer (Andersen et al., 1984). In the original study, irrigation pumpage from a bedrock aquifer located in northwestern Indiana was believed to be the cause of declining water levels in an overlying surficial aquifer. To determine the validity of the allegation, a three-dimensional computer model of the regional hydrogeologic system was developed. The hydrogeologic system was idealized into three main stratigraphic units: (1) a bedrock aquifer (The Limestone-Dolomite Aquifer), (2) a confining bed (the Clay-Till Aquitard), and (3) a surficial aquifer (the Kankakee Sand Aquifer). For a detailed description of the geology and hydrology of the study area the reader is referred to Bergeron (1981). Although the original study was quite complex, involving muitiple pumping periods as well as numerous sensitivity analyses on confining bed parameters, the present problem used for benchmarking purposes involves oniy one pumping period and utilizes the final model discretization and hydrogeologic parameters presented in Andersen et al. (1984).

The problem was simulated using FTWORK, MODFLOW, and CFEST. For the block centered finite-difference codes, FTWORK and MODFLOW, the areal problem domain was discretized into 25 and 27 grid blocks in the $x$ - and $y$-directions, respectively. As shown in Figure 3 , variable grid block dimensions were used, with finer discretization in the vicinity of pumping wells and gradually increasing toward the model boundaries. Grid block dimensions vary from 1626 to $42440 \mathrm{ft}$. A comparable discretization scheme was used in the mesh-centered finite-element code, CFEST. The grid line coordinates for the CFEST model were chosen to preserve the areal coordinates of the grid block centers from the block centered finite-difference models. The location of the computational nodes formed by the intersection of grid lines of the mesh centered grid thus correspond to the nodes located at grid block centers of the block centered grid. The CFEST mesh design resulted in 
27 and 29 grid lines for the $x$ - and $y$-directions, respectively.

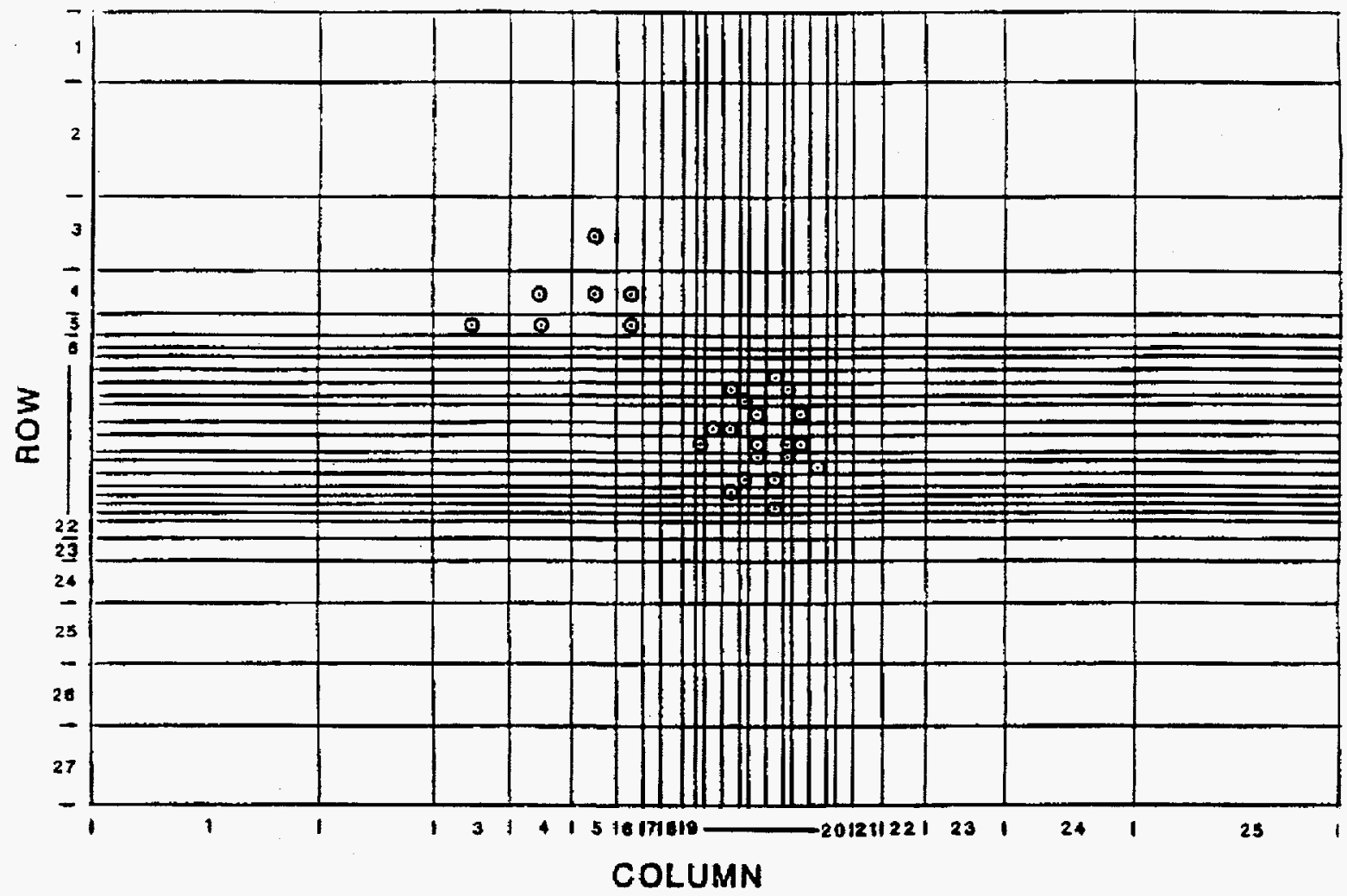

Figure 3. Grid spacing and location of pumping centers used in FTWORK and MODFLOW simulations of Probiem 6.

The vertical dimension in the FTWORK and MODFLOW models was discretized into 9 layers; 2 for the surficial aquifer, 5 for the confining bed, and 2 for the bedrock aquifer. The layer thicknesses vary from 8 to 92 feet with the finer discretization occurring with in and adjacent to the confining bed. The fine grid spacing was used to provide a better approximation of the large hydraulic gradients expected within the confining bed as a result of the large contrast in hydraulic conductivity between the aquitard and aquifer. The vertical grid spacing in both models is accounted for in a vertical conductance term VCONT, which also includes the vertical hydraulic conductivity. The conductance is given by:

$$
\operatorname{VCONT}_{k, k+1}=\frac{2}{\frac{\Delta z_{k}}{k_{z k}}+\frac{\Delta z_{k+1}}{k_{z k+1}}}
$$

where $\Delta_{z k}=$ thickness of 1 ayer $k$ and $K_{z k}=$ vertical hydraulic 
conductivity of layer $k$.

A harmonic mean is used in the formulation of the VCONT term. This can be compared to a series flow approximation; flow is primarily controlled by the lowest hydraulic conductivity. In two respects, the vertical discretization for the CFEST model is not directly comparable to that used in FTWORK and MODFLOW. First, the discretization is also mesh centered in the vertical for CFEST as opposed to a block centered conceptualization in FTWORK and MODFLOW. Therefore, vertical grid 1 ine coordinates in the CFEST model do not occur at grid block centers but rather at the top and bottom of each grid block. Secondly, due to extremeiy large memory requirements in CFEST, it was necessary to eliminate one layer within the confining bed by combining layers 4 and 5. The overall layer dimensions for all three models are identical, although the location of the computational points are different.

Homogeneous aquifer parameters were used within each layer. The contrast in hydraulic conductivity between the confining bed and aquifers is approximately 5 orders of magnitude. There is some variation in input of parameters; for exampie FTWORK and CFEST use specific storage and layer thickness to derive a storage coefficient while in MODFLOW storage coefficient is input directly.

The boundary conditions used by all the models are no-flow around the perimeter of the model, the top of model, and the base of the model. The areal boundaries are located far enough from pumpage stresses so that drawdown does not extend to the boundaries. The base of the bedrock aquifer is assumed to be an impermeabie boundary. Although the surficial aquifer is unconfined, it is modeled as a confined aquifer with unconfined storage properties. This was done because drawdown in the surficial aquifer was not expected to significantly alter the saturated thickness of the surficial system. Twenty-six pumpage centers were inciuded in the model. In order to include pumpage in the entire thickness of the bedrock aquifer, pumpage was apportioned to the layers representing the bedrock aquifer. In the FTWORK simulation, 26 wells were specified; in the MODFLOW simulation, 52 wells were specified; in the CFEST simulation 78 wells were specified. The varying numbers of wells are a resuit of the method of input and number of affected nodal layers; all of the above schemes result in the same total pumpage. The location of the pumpage centers are superimposed on the block-centered grid in Figure 3.

The model was originally developed to assess the independent effect of pumpage on the aquifer system. Hence, no recharge or other external stresses were specified and an initial condition of $0.0 \mathrm{ft}$ was used for hydraulic head. Because of the initial conditions, the head values computed by the model are equivalent to drawdown.

In FTWORK and MODFLOW an increasing time stepping scheme was used to provide fine time discretization in early time when heads were changing rapidly and coarse time discretization in later time. In the CFEST simulations it was advantageous to use a uniform time stepping scheme. This was done to avoid reforming the coefficient matrix for each time step. Initial attempts to use the increasing time-stepping

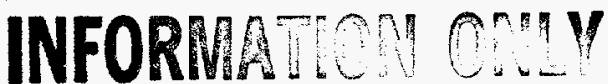


scheme employed by FTWORK and MODFLOW reveated that this approach for CFEST was unworkable in a practical sense for such a large problem. In all cases the models were run to simulate a 32-day pumping period.

Different solution schemes were used in the three models. MODFLOW used the iterative Strongiy Implicit Procedure (SIP), FTWORK used the iterative Slice Successive Over-Relaxation method (SSOR), while CFEST used a direct solution scheme. Closure criterion for the iterative schemes was set at $0.01 \mathrm{ft}$.

Comparison of hydraul ic heads obtained from the three models are generally favorabie. FTWORK and MODFLOW produced neariy identical resuits, with a maximum difference of $0.02 \mathrm{ft}(26.45 \mathrm{ft}$, FTWORK; 26.43 ft MOOF(OW) at the node with greatest drawdown. The similarity between FTWORK and MODFLOW solutions is expected; they are both based upon a block-centered finite-difference methodology and both employ similar iterative solution schemes. Because FTWORK and MODFLOW were in almost exact agreement, oniy FTWORK results are compared to CFEST results.

Contour maps of drawdown in the bedrock aquifer at the final time step are shown in Fjgure $4 a$ and $b$ for the FTWORK and CFEST simulations, respectively. In a regional sense the maps are nearly identical. Areas of greatest discrepancy occur in the immediate vicinity of pumping wells, and away from the wells the results are in good agreement. The maximum difference in drawdown occurs at the node representing the well with the greatest discharge'. CFEST predicts a drawdown of $31.70 \mathrm{ft}$ compared to $26.45 \mathrm{ft}$ for FTWORK and $26.43 \mathrm{ft}$ for MODFLOW. In genera1, CFEST predicts larger drawdowns at the well nodes while FTWORK predicts slightly larger drawdowns away from the pumping wells. This is shown in Figure 5 which depicts drawdown along a crosssection running through the wellfield. The discrepancy between the finite-difference methods and the finite-element method is expected. In general, the finite-difference methods are based on averaging heads across an entire block, white the finite-element methods compute values at the nodes themselves. Because of this, the effect of a pumping well will be more pronounced at the well using the finite-element method. Whereas, away from the wells, the finite-difference methods show slightly higher drawdown in order to preserve mass.

Layer-by-layer comparisons within the aquitard are not applicable for this problem because nodal layers are located at different elevations. A comparison was possible for the bedrock aquifer because flow is predominantly horizontal and hence only slight variation in head occurs with elevation. Although a direct comparison within the aquitard is not possible, it is possible to show a profile of heads within the aquitard for the various models (Figure 6). Again, the comparison is generally favorable. 

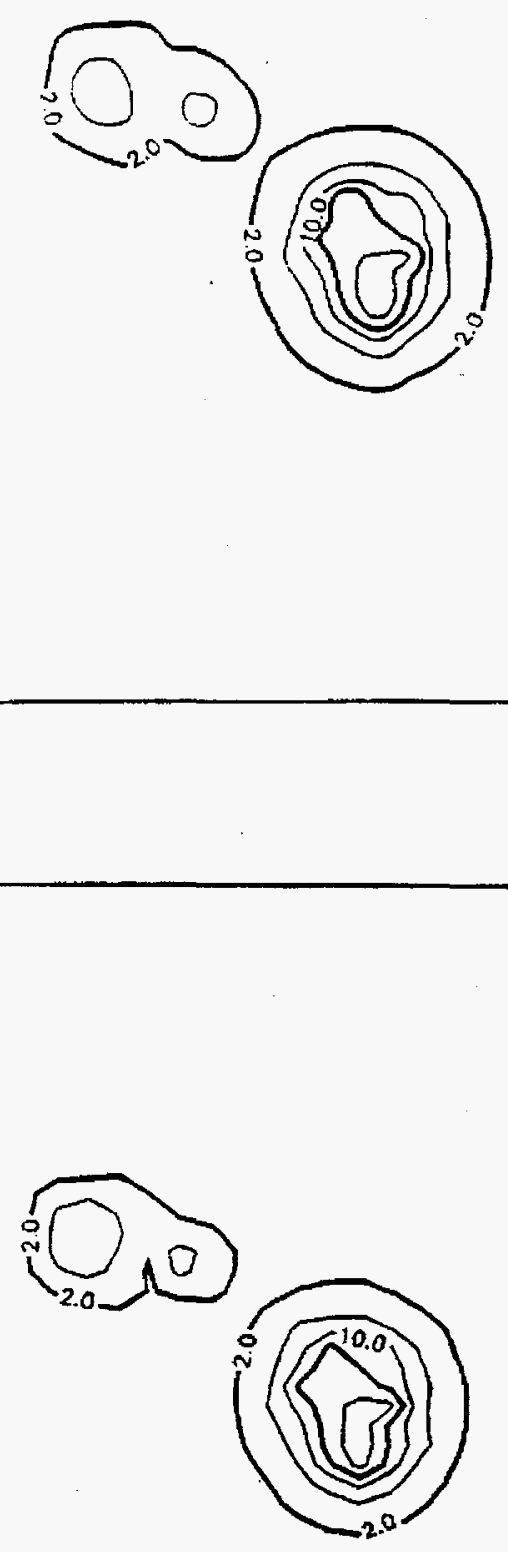

Figure 4. Orawdown (ft) computed by FTWORK (a) and CFEST (b) in the bedrock aquifer at the final time step. 


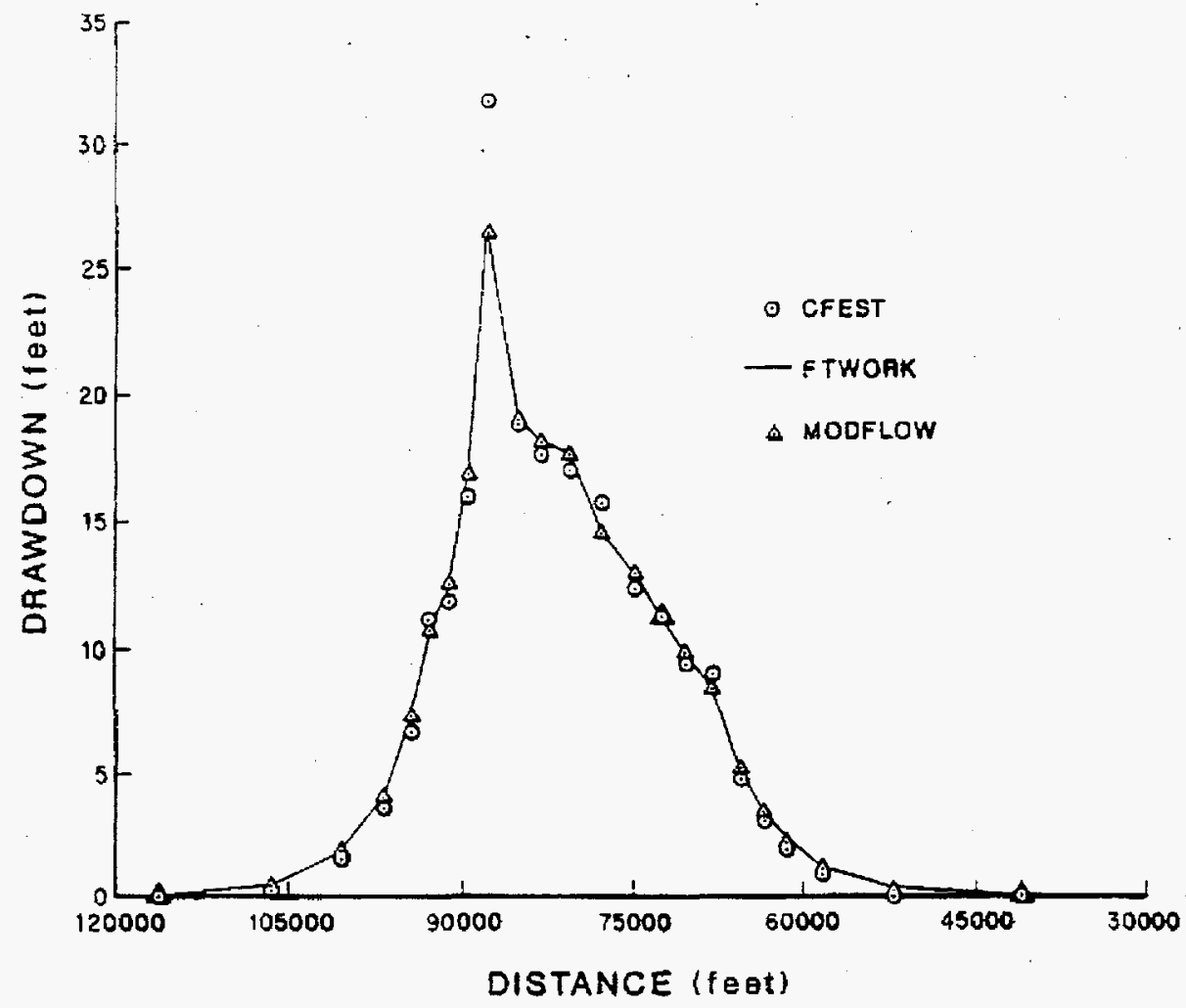

Figure 5. Drawdown ( $f t$ ) along a cross-section running through column 15 (of the finite-difference grid) computed by FTWORK, MODFLOW, and CFEST in the bedrock aquifer at the final time step.

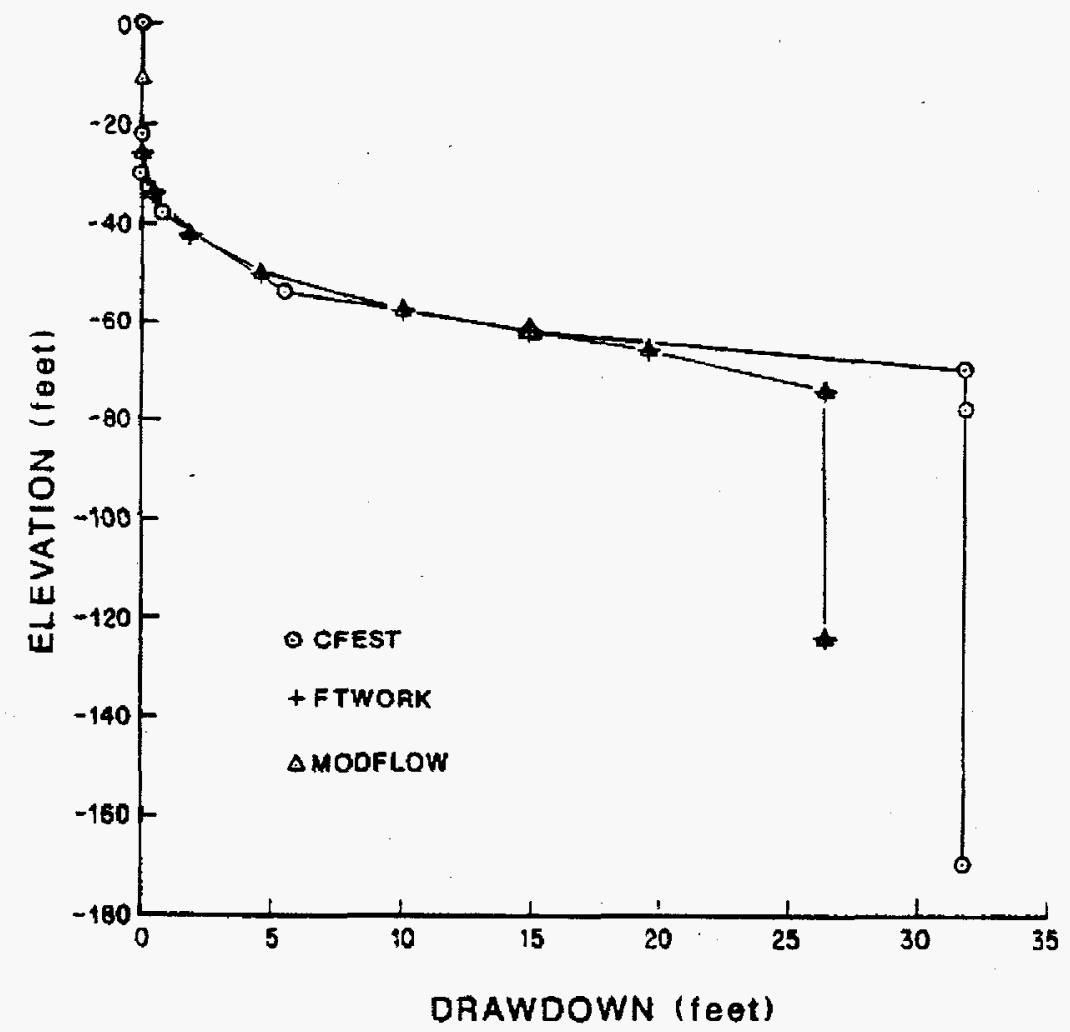

Figure 6. Profile of drawdowns within the multilayer aquifer system computed by FTWORK, MODFLOW, and CFEST at column 15 row 17 of the finite difference grid at the final time step. 
Within the surficial aquifer, the FTWORK simulation predicts a larger area of influence while the CFEST simulation predicts somewhat larger magnitudes of drawdown on a localized scale. This phenomenon was also noted for the bedrock aquifer; in fact the head distribution within the surficial system is a direct reflection of the head distribution in the lower system. In both cases, drawdown in the surficial system is minimal $(\leq 0.01 \mathrm{ft})$ as was concluded in the original study by Andersen et a1. (1984).

This problem was originally discretized for application of a finite-difference model. The finite-element grid used for the CFEST simulations was designed so computational points corresponded directly to the finite-difference computational points. Consideration was not given in the CFEST mesh design to take advantage of the features of the finite-element method. Thus, it is likely that a more efficient grid design could have been made if a node-to-node comparison had not been desired. In fact, due to the higher order approximation inherent in the finite-element method, it is also likely that the CFEST solution is more accurate than the FTWORK and MODFLOW solutions.

The finite-difference codes were substantially more efficient than the CFEST code. There are several differences in the method of application that render a direct comparison of effeciency to be somewhat misleading. First, the grids were not optimized for each code. Less nodes could probably have been used in the finite-element simulation to obtain similar accuracy as the finite-difference methods. Reduction in the number of nodes would have reduced the CPU time for the CFEST simulation. Secondly, a different time stepping scheme was used in the CFEST simulation than the FTWORK and MODFLOW simulations. This was done to optimize the CFEST computations; CPU time would have been much higher if non-uniform time steps had been used. Potential users of the codes should be aware that each code has distinct advantages for certain applications. For this application, the finitedifference codes are capable of handling the problem and therefore are economicaliy advantageous over the finite-element code. The generality of the CFEST code is not necessary for this application but nevertheless is employed in the solution scheme. There may be other circumstances, such as when accurate characterization of geometry is crucial where the finite-difference models would be inaccurate or inefficient to use.

To further evaluate the differences between the results of the finite-element and finite-difference codes, the problem was run with another finite-element code, SWICHA (Huyakorn et al., 1986). The resuits obtained were comparable to those of CFEST. A substantial reduction in CPU.time was achieved by using SWICHA and can be attributed to the influence coefficient technique used by that code.

\section{Additional Benchmark Problems}

Additional benchmarking of the FTWORK code was based on modeling studies performed at the Savannah River Plant (SRP), a major Department of Energy facility located near Aiken, South Carolina. The study area 
is located within the SRP boundary in an area known as the General Separations Area. The problem involved modeling of three-dimensional steady-state groundwater flow and transient solute transport in a setting with complex geometry and boundary conditions.

The results of the groundwater flow simulation were very similar for MODFLOW and FTWORK. Minor discrepancies in hydraulic head on the order of hundredths to tenths of a foot were present between the models. This variation appeared to be random. Resultant components of discharge and sources are comparable for the two codes.

Some discrepancies between these codes and SWIFT II were noted. These differences are attributed to different methods of treating grid blocks that desaturate. The logic within FTWORK and MODFLOW removes grid blocks from further calculation that go dry during the course of iteration once a grid block has desaturated, it is not allowed to resaturate if the proper conditions occur. Grid blocks may inadvertently go dry as a result of an oscillatory or over-accelerated iteration scheme. Thus, it is not necessarily a physical phenomenon that causes desaturation. It is important to note that desaturated grid blocks may cause significant barriers to fiow, particularly in the vertical direction. In the SWIFT code, grid blocks that desaturate are not removed from calculation as they were in the other codes. Rather, the head is set to a minimum percent for the grid block thickness. This partial saturation allows the grid block to resaturate if the right conditions occur and also prevents barriers to flow from occurring.

It should be pointed out that the amount and location of grid blocks that go ory are very sensitive to the iteration parameters that are chosen. By decelerating the iteration or approach to the solution, the amount of grid blocks that are inadvertently dropped from the simulation is minimized. For this problem a SIP acceleration parameter of 0.55 was found to produce desaturation similar to that observed in FTWOrk using an SSOR acceleration factor of 1.3. The user of either code should be aware of the potentially different solutions that can occur in situations similar to this application as a result of choice of acceleration parameter.

FTWORK's three-dimensional solute transport modeling capabilities were also tested for this particular problem. The formulation of this problen was based on an earlier study (Duffield et al., 1987) which assessed lead migration from a waste facility at the SRP site. Comparisons between FTHORK and SWIFT are generally favorable. Much of the difference between the two results may be attributed to slightly different flow fields that were used. The magnitude of the discrepancy appears to be reasonable and acceptable given the differences in the initial problem specification.

\section{CONCLUSIONS}

The finite-difference model that was described earlier in this paper, FTWORK, performed very well when compared to analytical 
solutions and to the results computed by other accepted groundwater flow and solute transport codes. The benchmarking procedure also brougint to light several interesting differences in the approximation methods used by the various codes. The differences that were present in model results were justifiable and deemed acceptable. The code is currently being used for a regional modeling study of the hydrogeologic system underlying the Savannah River Plant.

\section{ACKNOWLEDGEMENT}

The information contained in this article was developed during the course of work under Contract No. DE-AC09-76R00001 with the U.S. Department of Energy. 


\section{REFERENCES}

Andersen, P.F., R.M. Cohen, and J.M. Mercer, 1984. Numerical modeling as a conceptual tool to assess drawdown in a multiaquifer system. Proceedings of the Symposium on Practical Appiications of Ground Water Models, National Water Well Association, Columbus, Ohio.

Bear, J., 1979. Hydraulics of Groundwater, McGraw-Hi11, New York.

Bergeron, M., 1981. Effect of Irrigation Pumping on the Ground-Water System in Newton and Jasper Counties, Indiana: U.S. Geological Survey, Water Resources Investigations 81-88.

Duffield, G.M., D.R. Buss, C.P. Spalding, and L.A Plante, 1987. Characterization of Groundwater Flow and Transport in the General - Separations Area, Savannah River P1 ant: Effect of Closure Cap on Solute Transport Mixed Waste Management Facility (643-28G), December 23, 1987 GeoTrans, Inc. report to Savannah River Plant.

GeoTrans, Inc., 1987a. FTWORK: Groundwater flow and solute Transport in three dimensions, version 1.6 , documentation (REVIEW DRAFT), GeoTrans Report, October 1987, 93 pp.

Gupta, S.K., R. Cole, T. Kincaid, and M. Monti, 1981. Coupled Fluid, Energy, and Solute Transport (CFEST) Model: Formulation and User's Manual, BMI/ONWI-660, Office of Nuclear Waste Isolation, Battelle Memorial Institute, Columbus, Ohio.

Huyakorn, P.S., J.W. Mercer, P.F. Andersen, and H.O. White, Jr., 1986. Saltwater intrusion in aquifers: Deveiopment and testing of a three-dimensional finite-element model, Water Resources Research, 23(2): 293-312.

Kipp, K.L., Jr., 1987. HST3D: A computer code for simulation of heat and solute transport in three-dimensional ground-water flow systems, U.S. Geological Survey Water Resources Investigations Report $86-4095,517$ pp.

McDonald, M.G., and A.W. Harbaugh, 1984. A modular three-dimensional finite-difference groundwater flow model, U.S. Geological SUrvey Open File Report 83-875.

Ogata, A., and R.B. Banks, 1961. A solution of the differential equation of longitudinal dispersion in porous media, U.S. Geological Survey Professional Paper No. 411-A.

Reeves, M., D.S. Ward, N.D. Johns, and R.M. Cranwell, 1986. Theory and implementation for SWIFT II, the Sandia waste-isolation flow and transport model for fractured media, Release 4.84, NUREG/CR-3328, SAND 83-115a, Sandia National laboratory, Albuquerque, NM. 
Theis, C.V., 1935. The relation between the Towering of the piezometric surface and the rate and duration of discharge of a well using groundwater storage, Trans. American Geophysical Union, 2 , pp 519-524.

Venetis, C., 1958. On the impulse response of an aquifer, Builetin of the International Association of Scientific Hydrology, pp 136-136.

Wattenbarger, R.A., and D.H. Thurnau, 1976. Application of SSOR to three-dimensional reservoir probiems, Paper presented at 4th Symposium on Numerical Simulation of Reservoir Performance, Soc. of Petrol. Eng., AIME, Los Angeles, Calififornia, (Feb. 19-20).

Weaver, W., Jr., 1967. Computer Programs for Structural Analysis, D. Van Nostrand Company, Inc., Princeton, New Jersey.

Wilson, J.L. and P.J. Milier, 1978. Two-dimensional plume in uniform groundwater flow, Journal of the Hydraulics Division, Amer. Society of Civil Engineers, 104, HY4, pp.

Woo, P.T., and A.S. Emanual, 1976. A block successive over-relaxation method for coupled equations, Paper presented at East Annual Fall Meeting, Society of Petroleum Engineers, AIME, New Orleans, Louisiana, (0ct. 3-6). 


\section{BIOGRAPHICAL SKETCHES}

Paul N. Sims obtained his B.S. and M.S. degrees in Civil Engineering from Auburn University. Since completing his M.S. degree in 1986, he has been employed as an engineer with GeoTrans, Inc. Mr. Sims has been active in numerical model development and testing as well as a variety of field related activities. [GeoTrans, Inc., 4350 Brownsboro Road, Suite 239, Louisville, Kentucky, 40207, (502) 893-4590]

Peter $F$. Andersen attended Northern Arizona University and Auburn University where he received and M.S. degree in Civil Engineering in 1980. Prior to graduate study he work as a field engineer for the Auburn University Aquifer Thermal Energy Storage (ATES) projects. As a Principal Engineer and Vice President of GeoTrans, Inc., Mr. Andersen has been involved with application of numerical models at a variety of hazardous waste sites modeling sait-water intrusion studies of two sites in Florida, numerical model development and modification, as well as groundwater modeling short courses. He is a registered Professional Engineer in the State of Virginia. [GeoTrans, Inc., 250 Exchange P1ace, Suite A, Herndon, Virginia, 22070, USA, (703) 435-4400]

Dale $E$. Stephenson is a research staff geologist engineer with E.I. du Pont de Memours and Company at the Savannah River Laboratory in Aiken, South Carolina and holds degrees in geology, geophysics, and civil engineering. His experience has been in exploration/production, underground facilities, environmental geology, and waste disposal with emphasis on groundwater problems. [E. I. du Pont de Nemours and Co., Savannah River Laboratory, Aiken, South Carolina, 29808, USA, (803) 725-5217]

Charles R. Faust received his B.S. and Ph.D. in Geology from Pennsyivania State University in 1967 and 1976 . Until recently, he was a Hydrologist with the Water Resources Division, U.S. Geological Survey. His interests there involved thermal pollution in rivers, geotherma reservoir simulation, and fluid flow in fractured rocks. Presentiy he is executive vice president of GeoTrans., Inc., where he is interested in quantitative evaluation of hazardous waste, NAPL migration, and radionuclide migration in fractured rocks. [GeoTrans, Inc., 250 Exchange Place, Suite A, Herndon, Virginia, 22070, USA, (703) $435-44001$ 